\title{
Opinions of adolescents on prevention related to sexting:
}

\section{A Q-methodology study}

\section{Yara Barrense-Dias ${ }^{\mathrm{a}}$, Christina Akre ${ }^{\mathrm{a}}$, Joan-Carles Suris ${ }^{\mathrm{a}}$, André Berchtold ${ }^{\mathrm{b}}$}

Affiliations: ${ }^{a}$ Research Group on Adolescent Health (GRSA), Center for Primary Care and Public Health (Unisante) - University of Lausanne, Lausanne, Switzerland; and ${ }^{\mathrm{b}}$ Institute of Social Sciences \& NCCR LIVES, University of Lausanne, Lausanne, Switzerland.

Address correspondence to: Yara Barrense-Dias, Research Group on Adolescent Health (GRSA), Center for Primary Care and Public Health (Unisante) - University of Lausanne, Route de la Corniche 10, 1010 Lausanne,Switzerland, Yara.Barrense-Dias@unisante.ch, +41213146946

Funding: This study was funded by the Departement Universitaire de Médecine Sociale et Communautaire (DUMSC) / University Department of Social and Community Medicine

Conflict of interest: none to declare. 


\begin{abstract}
Introduction Sexting has attracted the interest of researchers, media and public opinion but its definition still does not reach consensus. This gap may lead to diverging prevention messages. This study investigated the opinions of youths on a set of sexting-related preventive measures. Methods In 2018, 48 youths (27 females) with a mean age of 16.2 participated in the study. To assess opinions of youths on sexting-related prevention, we conducted a Q-methodology study, a mixed methods research, in Lausanne (Switzerland). The final Q-set was constituted of 58 statements reflecting a wide range of key-messages, key-actors and materials. Each participant was asked to rank-order the 58 cards using a grid ranging from -5 (most disagree) to +5 (most agree).
\end{abstract}

Results Five different profiles of considering sexting-related prevention were found: Focus on consequences, Sex education and testimonies, Focus on guidelines, Focus on training/information and Peer prevention. The typical scenario used in many prevention campaigns illustrating a girl who is victim of a nonconsensual sharing perpetrated by a boy was not appreciated. The topic of the Internet was not considered as an appropriate gateway to discuss sexting. Pressure and bullying issues as topics to discuss in a sextingrelated prevention were the most consensual statements. Conclusions This study highlighted the need to offer a multidisciplinary, multi-resource and multi-concept approach in sexting-related prevention. Broader values such as respect and consent must be integrated. Consensual sexting must be clearly differentiated from nonconsensual dissemination. Policy implications and future directions, including prevention strategies, are discussed.

Keywords Sexting; Prevention; Education; Q-Methodology; Adolescents 


\section{Introduction}

Recently youths' online sexual behaviors have attracted the interest of researchers, mass media and public opinion. Sexting is one of these behaviors but its definition and measure still does not reach consensus (Barrense-Dias, Berchtold, Surís, \& Akre, 2017a; Van Ouytsel, Walrave, \& Ponnet, 2018). In Switzerland, the last survey (Suter et al., 2018) on media use among youths (12-19 year-olds) revealed that $12 \%$ had already sent erotic or flirtatious images of themselves and $40 \%$ had already received this kind of content. A national survey conducted in 2017 (Barrense-Dias et al., 2018a) among young adults found that more than $50 \%$ of participants had already sent sexy images of themselves, $62 \%$ received such images and $15 \%$ shared a received-content with a third party. This practice seems to be quite frequent among youths and increase with age.

In terms of law, Switzerland is currently facing a debate with sexting that goes wrong when, for example, a content is disseminated without consent, especially when youths under the age of 16 are involved. For such a case, child pornography legislation could be used: Any person who offers, shows, passes on or makes accessible to a person under the age of 16 pornographic documents [...] is liable to a custodial sentence [...]. (Swiss criminal code). However, controversies surround this use as law ignores consensual sexting and because the victim of nonconsensual distribution could be treated and prosecuted as a child pornography producer. Another difficulty with the use of this legislation is how to define pornography in a sexting context. If genital parts are visible, it is quite simple but if they are not, a case-by-case analysis must be conducted. If the content is not considered as pornographic, the procedure is abandoned unless other charges are possible such as blackmail or threats. Civil law can also be used with legislation on the protection of personality. The legislation on child pornography is also 
used in other countries but has been regularly disapproved (Crofts \& Lee, 2013; Holoyda, Landess, Sorrentino, \& Friedman, 2018; Levick \& Moon, 2010; Salter, Crofts, \& Lee, 2013).

Despite the fact that the number of scientific publications and prevention campaigns have significantly increased since the first study on sexting among youths (The National Campaign to Prevent Teen and Unplanned Pregnancy, 2008), there are still controversies about defining it as a normal sexual activity or as an abusive behavior (Barrense-Dias et al., 2017a; Döring, 2014; Klettke, Hallford, \& Mellor, 2014; Wolak \& Finkelhor, 2011; Wolfe, Marcum, Higgins, \& Ricketts, 2016). This gray area does not help to clarify the legal situation.

This lack of a clear definition may lead to assimilation of consensual and nonconsensual sexting (Krieger, 2017) and diverging awareness messages. In this line, some authors (Albury \& Crawford, 2012; Powell \& Henry, 2014; Van Ouytsel, Walrave, \& Van Gool, 2014) criticized several campaigns that primarily focused on risk management of potential victims, especially girls, rather than addressing perpetrators of problems linked to sexting such as non-consensual distribution to others. Furthermore, abstinence messages were sometimes used to stop consensual sexting while a recent trend called for safe sexting and condemned nonconsensual dissemination (Döring, 2014). In Switzerland, the main prevention campaign focusing on sexting was released in 2013 (Pro Juventute, 2013) and consisted of a poster illustrating a boy and a girl who had their intimate photo disseminated and wore a scarf of Mister the whole school knows me naked and Miss my ex shared my photo. The slogan was: Sexting can make you famous, even if you do not want to. This campaign was therefore aimed directly to communicate a message of abstinence to potential victims and first senders. Since then, the subject of 
sexting has been approached in other interventions but in broader themes such as Internet use.

While educational and preventive projects linked to sexting multiplied, we still have relatively little perspective on their efficiency among youths. A study (Jørgensen, Weckesser, Turner, \& Wade, 2018) explored recommendations from youths to improve education in school and determine how stakeholders should address sexting. The paper emphasized the importance to use youths' voice for the development of effective interventions.

Therefore, this exploratory study aimed to gather the opinions of youths on prevention linked to sexting. The proposed preventive measures explored elements such as keyactors, key-messages, targets and material to obtain a large overview of what youths expect about sexting issues.

\section{Methods}

To assess youths' opinions on prevention related to sexting, we conducted a Qmethodology study (Brown, 1993, 1996; Stephenson, 1935; Watts \& Stenner, 2005). This mixed method allows to bring out shared factors, profiles or "patterns of views" (Scott, Baker, Shucksmith, \& Kaner, 2014) from the subjectivity of each participant and the great variability of opinions on a topic. In other words, the Q-methodology is “[...] particularly suitable for researching the range and diversity of subjective understandings, beliefs and experiences[...]. At the same time, it facilitates the identification of similarities, the construction of broad categories or dimensions of the phenomenon being investigated and the exploration of patterns and relationships within and between these dimensions."(p.104) (Shinebourne \& Adams, 2007). Given the different forms that prevention can take this method seemed particularly appropriate for our purpose. This 
method has already been used successfully among adolescents and young adults (Hislop, Mason, Parr, Vale, \& Colver, 2016; Jedeloo, van Staa, Latour, \& van Exel, 2010; Scott et al., 2014; Tielen, van Staa, Jedeloo, van Exel, \& Weimar, 2008). Even if some controversies surround the definition of Q-methodology as a mixed-method, it has been clearly shown that it fulfills the conditions of a mixed-method (Ramlo \& Newman, 2011). Indeed, Q-methodology “[...] shares with qualitative methodologies the aim of exploring subjectivity; however, statistical techniques are used to reveal the structure of views"(p.38) (Bashatah, 2016). Ethic clearance was given by the cantonal ethics committee.

\section{Participants}

Between February and April 2018, 48 youths (27 females, mean age 16.2 years) participated in the study (Table 1). The Q-methodology does not require a representative sample as the focus is on response profiles and not individual persons(Brown, 1980). Moreover, a relatively small sample is tolerated with a number between 40 and 60 participants considered as sufficient (Watts \& Stenner, 2005), even if it is also possible to use smaller groups (Shinebourne, 2009). However, this method requires a sample that is representative of diverse viewpoints. Therefore, to ensure a larger representation of youths, we used an ad to recruit participants from all over the canton. The ad was posted on a job recruitment website for youths (15-25 year-olds) presenting our research as a scientific study that aimed to collect opinions on prevention linked to sexting. When youths contacted us, we used the snowball method to recruit further participants, especially for those under the age of 15 . Forty-one came to our office by their own means. As we had difficulties to recruit boys, 7 additional participants were drawn from a public school through their teacher and the activity was organized in their school after classes. 
Participants were recruited independently of their sexting activities. Participation was voluntary, even in the school setting. For children under the age of 14 (based on the Swiss Federal Act on Research involving Human Beings) and those taking part in this study in the school perimeter (with the agreement of the General Directorate of Compulsory Education), parents received an information letter and signed a consent form for their child participation. In Switzerland, if a research project entails minimal risks only, legal minors aged 14 years or more give informed written consent alone. All youths received an information letter and signed a consent form to participate before the session. Important elements such as research objectives and confidentiality issues were also repeated orally. They all received a gift card worth $\sim 30$ US\$.

\section{$Q$-set}

The first step of this method is to create a set of statements (between 40 and 80 (Shinebourne, 2009; Watts \& Stenner, 2005)) on the studied topic that represent opinions and not facts. These statements can be derived from different sources such as qualitative research, literature or personal ideas (Wood, Griffiths, Derevensky, \& Gupta, 2002). In our case we first combined results of previous focus groups with youths, teachers and parents (Barrense-Dias, Suris, \& Akre, 2017b; Barrense-Dias, Surís, \& Akre, 2019), and results of a non-exhaustive inventory of 51 preventive and educational projects linked to sexting (Barrense-Dias, De Puy, Romain-Glassey, \& Suris, 2018b). Then, the authors completed the statements by making other proposals. After discussion between the authors until reaching consensus, 58 statements were part of the final Q-set (Table 3), reflecting a wide range of key-messages, key-actors and prevention materials. Each statement was printed on a paper card.

\section{$Q$-sort}


The Q-sort phase is the statements' ranking procedure (Watts \& Stenner, 2005). After providing general information, participants were first asked to read the cards and divide them into three categories (Hislop et al., 2016; Jedeloo et al., 2010; Tielen et al., 2008): agree, neutral and disagree. They could ask questions if something was unclear. This first step allowed them to become familiar with the statements. Participants were then asked to rank-order the 58 cards using a grid ranging from -5 (most disagree) to +5 (most agree) with the zero defined as neutral (I do not know) and following a forced quasi-normal distribution (Figure 1). Finally, once participants were satisfied with their ranking, they were asked using paper and pencil to explain the place of the four extreme cards ranked -5 and +5 (Jedeloo et al., 2010), suggest additional statements and/or indicate if a statement was unclear or problematic (Shinebourne, 2009). In addition to their sort, only gender and age were collected. The first author, who was present and available for questions, saved the ranking provided by each participant by taking a picture of the grid. The oral questions some participants asked were exclusively on the final purpose of the study and the ranking procedure. The ranking phase took 45-60 minutes.

\section{Statistical analysis}

The analysis aimed to identify groups of respondents whose grids represented shared viewpoints that were distinct from others. The Q-method used Q-type or by-person factor analysis that focused on individuals rather than statements (Stephenson, 1935; Watts \& Stenner, 2005). Using the Ken-Q Analysis web application (https://shawnbanasick.github.io/ken-q-analysis), we performed a factor analysis designed to maximize the interpretability of the resulting profiles.

First, meaningful factors were extracted from the initial correlation matrix between Qsorts using a centroid factor extraction. Second, extracted factors were rotated using 
varimax technique to simplify the structure of data and improve the interpretability. Third, an automatic flagging process was performed to identify the most representative Q-sorts associated with each factor (Table 1). Fourth, factors to be interpreted were selected with two criteria (Watts \& Stenner, 2005). The first criterion was based on the eigenvalue which must be $>1.00$. The second one required that two Q-sorts, at least, were selected in the flagging process to be considered as 'factor exemplars' representing the characteristic configuration of the factor or profile. Finally, Z-scores were calculated to determine the rank of each statement for each factor and a factor comparison was performed to identify consensual and distinguishing statements between pairs of factors. In addition to the factor analysis, we established the trends that all factors or profiles presented. We fixed the significance level at 0.05 .

As participants also explained their choice in free-text fields, we performed a qualitative analysis and associated results to the statement in question. This qualitative part used the explanatory sequential design of mixed methods: the integration of qualitative data served to explain and interpret the ranking results (Figure 2). Written comments were translated by the first author from French into English.

\section{Results}

The factor analysis resulted in five profiles of opinions. These five profiles accounted for $55 \%$ of the total information contained in the Q-sorts: $42 \%$ were explained by the first factor, $4 \%$ by the second one and $3 \%$ for each of the other factors. Main characteristics of the flagged Q-sorts associated to each factor or, in other words, the Q-sorts that mainly defined each factor, appear in Table 2. We also include the main characteristics of all participants to see on which factor their opinions are best represented.

\section{Profile A: Focus on consequences}


Youths on the first factor wanted to be informed on the legal consequences related to sexting activities $(S 25,+5)$. Regarding this statement, explanations written by participants mostly focused on legal consequences of a nonconsensual dissemination compared to consensual sexting: "Talking about legal consequences could remind people who use blackmail or other means of pressure on their victims that the dissemination of these images without the consent of the person is completely illegal, and thus discourage them from their acts."(Male, 17). In addition to legal consequences, these participants recommended discussion on psychological consequences (S43) and, again, they mostly referred to the nonconsensual dissemination: "Talking about mental and social consequences is, I think, a quite effective way to make youths understand that sexting is not a funny subject in the case of a person who is seriously affected by the dissemination of photos."(Male, 17). This distinction between consensual sexting and potential problems linked to the activity such as nonconsensual distribution to others was also reflected in the statements that differentiated these two dimensions. Indeed, compared to consensual sexting $(\mathrm{S} 3,+1)$, the prevention of the nonconsensual dissemination got more agreement $(\mathrm{S} 4,+3)$. Similarly, the prohibition of sexting between two consenting persons had a low rank $(S 28,-3)$. This distinction between the practice and its possible negative consequences could also be seen in S44 (+4), which postulated that prevention must include harassment and blackmail issues.

Using testimonies of victims was also considered as appropriate $(\mathrm{S} 26,+4)$ : “The use of testimonies is very useful. The public will be able to see the consequences of sexting."(Male, 15). These participants reported parental control on mobile phones as an inappropriate solution (S2, -5). Moreover, they did not give much space to parents. Indeed, both statements on parents(training (S10, -2) and discussion $(\mathrm{S} 21,-3))$ had low 
scores and, compared to other profiles, parents had the lowest rank and privacy was highlighted in their explanations: "Young people have the right to have their 'private life' without the parents blaming everything. It is the freedom to do what you want. And the more parents want to know what we do, the more we will hide."(Female, 15). Similarly, anonymity issues were also highlighted with the statement on a special phone line to get prevention advices and help $(\mathrm{S} 27,+4)$ : “[...] People who are victims of photos that are disseminated without their consent will [...] have a hard time talking to someone because the situation could be very embarrassing. This is why a help phone line and website can be very good for a victim feeling alone in sexting. Talking to a neutral person who is not known (and who will not be able to judge us) or finding a solution or help [...] can be easier."(Female, 18). In this line of neutrality, teachers were also placed in a lower rank than other profiles $(\mathrm{S} 18,-2)$, while, in line with the statement on legal consequences, the police was relatively high $(\mathrm{S} 17,+2)$ : “What always helps me realize is when the police come to school to warn us of something and give us a real example that shocks us and I think it is the best prevention. "(Male, 14). However, sexual educators were also positively considered as potential actors for sexting prevention $(S 1,+3)$. As they considered that prevention should not be genderspecific (S5, -4) and that boys and girls should not be separated to discuss sexting issues $(S 29,-4)$, they also had the opinion that awareness messages should not only use the example of a girl as the victim and a boy as the perpetrator of a nonconsensual dissemination (S47, -5).

\section{Profile B: Sex education and testimonies}

Youths on factor B followed the trend of factor A with the legal consequences statement $(\mathrm{S} 25,+5)$ and testimonies of victims $(\mathrm{S} 26,+5)$ but demonstrated some differences in 
terms of key-actors and gender-specific prevention. If the police (S17) was quite well ranked in profile $\mathrm{A}$, it was ranked -2 in profile $\mathrm{B}$. Indeed, these participants considered sex education classes as a more appropriate moment to address sexting $(\mathrm{S} 1,+4)$ : "Sex education classes are something that pupils often expect the most. Moreover, sex educators are more qualified to talk about sexting."(Male, 16). Even if these participants requested discussions on legal aspects, they also included larger topics such as pressure $(\mathrm{S} 46,+4)$ and consent issues(S37, +4). They also held the opinion that interventions should mainly focus on nonconsensual dissemination $(\mathrm{S} 4,+3)$, including the active witnesses who could continue the dissemination $(\mathrm{S} 20,+3)$, rather than focusing on consensual sexting(S28, -4);(S3, 0): "I think it is important to note that sexting can be "used" while respecting the individual. Indeed, an individual can be in relation with another and indulge in this kind of practice. You have to trust your partner and eventually discuss with her/him and specify that you want it to stay between you. Sexting can be enjoyed by both [partners] and go very well, without any harassment or defamation." (Female, 18). Compared to other profiles, gender differences were positively ranked. Indeed, the statement on gender-specific prevention $(\mathrm{S} 5,+2)$ and separated discussions by gender $(\mathrm{S} 29,+3)$ presented the highest ranks among the five profiles: "If girls have the opportunity to discuss it together without male presence, it will certainly be good for them. As for boys, there is a lot of work to do on the subject of consent and respect for others. "(Female, 17). Even though this group evaluated the fact of illustrating prevention with girls as victims and boys as perpetrators of dissemination less negatively than other participants, it remained negatively ranked (S47, -1).

These participants called for youth involvement in prevention development $(\mathrm{S} 8,+3)$ : "People who are most affected are youths, so they know the problem best. Their 
participation in prevention that is probably more targeted towards them would allow other youths to better understand and take prevention more seriously. Because youths tend not to listen to older people."(Female, 18). Finally, they did not agree with the statement that postulated that prevention related to sexting should be done in specific groups such as scouts, sports associations, etc.(S58, -4).

\section{Profile C: Focus on guidelines}

Participants on factor C considered that a procedure to follow (step by step) in case of problems linked to sexting could be a good solution $(\mathrm{S} 38,+5)$. This statement seemed to be considered as an additional mean because prevention alone would not be sufficient to eliminate all the problems: "You have to create a guideline: "If it happened to you what should you do?" I think we need to do prevention but I do not think that it will stop everything. That is why we must set up a procedure to follow."(Female 14). In the same line of a guideline, they also called for more information on reference persons $(\mathrm{S} 31,+3)$ : "We do not know who to contact, as we have very little prevention. We cannot talk to anyone in case of problems; it would be nice to have at least one person per school [...]. "(Female 16). They were also more neutral towards a parental filter on mobile phones $(\mathrm{S} 2,0)$.

These participants also thought that prevention should address bullying and blackmail issues $(\mathrm{S} 44,+5)$, as they agreed with the focus on the nonconsensual dissemination (S4, +4) rather than consensual sexting (S3, -2). They were also interested in receiving testimonies of victims as prevention material $(\mathrm{S} 25,+4)$. Compared to other profiles, they were not so interested in receiving information on legal consequences $(\mathrm{S} 25,0)$ and the police was negatively ranked $(S 17,-2)$. In terms of key-actors, they considered a more independent strategy: neither sex educators, school staff, parents nor peers received high 
ranks. On the contrary, they were more interested in prevention videos with YouTubers $(\mathrm{S} 15,+3)$. Focusing on girls as victims and boys as perpetrators was not positively assessed (S47, -4). Finally, compared to other profiles, they were more likely to consider that prevention should target potential victims to enable them to protect themselves (S36, $+3)$.

\section{Profile D: Focus on training/information}

Youths in factor D called for more training and information for youths $(\mathrm{S} 11,+5)$, as well as for teachers and parents, but with lower rankings $(\mathrm{S} 10,+2) ;(\mathrm{S} 12,+2)$. In this context of education, the place of parents was high as these participants considered that they must have a role in prevention linked to sexting $(\mathrm{S} 21,+4)$ : "I think the first people we listen to are our parents, if the parents talk to their children as soon as they have a mobile phone, it will influence the child [...]. "'(Male, 18). Sex education classes $(\mathrm{S} 1,+3)$ and teachers $(\mathrm{S} 18,+2)$ were also positively ranked. On the contrary, police $(\mathrm{S} 17,-1)$ and peer $(\mathrm{S} 24,-$ 1) prevention were not considered as positive. However, the statement on legal consequences received a positive ranking $(\mathrm{S} 25,+3)$.

For them, prevention related to sexting should include discussions on the possible psychological consequences such as risk of depression $(\mathrm{S} 43,+5)$. They also considered that consent issues $(\mathrm{S} 37,+4)$ and respect for others $(S 40,+4)$ should be part of such prevention: "I fully agree with this statement because respect for the other is essential. If we respect the other we will not send photos or videos, without her/his consent. If we respect and consider the person, there will be no reason to harm her/him and therefore the risk of harassment should not exist anymore."(Female, 18).

Targeting specific groups was negatively ranked (S58, -4). “And for specific groups it is not up to the [sport, scouting, etc.] instructor to talk about it to her/his participants. It 
must be the work of parents or qualified people."(Male, 15). Starting sexting prevention from the age of $8(\mathrm{~S} 7,-1)$ and forbidding consensual sexting $(\mathrm{S} 28,-2)$ were less negatively ranked than in other profiles.

\section{Profile E: Peer prevention}

The last group also called for more training and information on sexting for youths (S11, $+5)$. In terms of resources, they advocated for a system of peer prevention $(\mathrm{S} 24,+4)$ and sex educators had a rather positive place $(\mathrm{S} 1,+3)$. They were also quite positive with different types of prevention depending on age $(S 6,+3)$ but prevention about sexting should not start at age 8 (S7, -4): "Prevention at the age of 8 is too early. Between 11-13 years old, it would be ideal. "'(Male, 17). On the other hand, prevention should not be differentiated according to gender (S5, -4), and boys and girls should not be separated to discuss sexting (S29, -4). Likewise, girls should not systematically be portrayed as victims and boys as perpetrators of nonconsensual dissemination (S47, -5).

Police was highly ranked as a key-actor to do prevention in class $(\mathrm{S} 17,+5)$ and participants also called for more information on legal consequences of sexting $(\mathrm{S} 25,+4)$. Compared to other profiles, they were less interested in testimonies of victims because of the intimate nature of the topic (S26, -2): "It is a testimony but it remains personal, private."(Male, 16). In terms of content, sexting prevention should include discussion on the pressure that could be put on a person to obtain an intimate content $(S 46,+4)$ and respect for others $(\mathrm{S} 40,+3)$. These participants rather considered discussing sexting as part of a larger prevention on bullying $(\mathrm{S} 52,+3)$ : " $[\ldots]$ The problem is not sexting per se but the dissemination of content without consent of the person to whom this content belongs which often leads to bullying. "(Female 17).

\section{Consensus statements}


Some statements were negatively ranked on all profiles: Prevention linked to sexting should start at the age of 8 (S7), Sexting must be forbidden even between two consenting persons (S28), Prevention linked to sexting is useless (S33), Prevention related to sexting should highlight girls as victims and boys as authors of dissemination (S47), Doing nothing / not practicing sexting is the best prevention (S54) and Prevention related to sexting should be done in specific groups such as scouts, sports association, etc.(S58). On the contrary, some statements received positive rankings on the five profiles: Prevention related to sexting should address consent issues (S37), Prevention related to sexting should address respect for others (S40), Prevention related to sexting should address pressure that can sometimes be experienced to obtain a photo / video (S46), and Sexting theme should be included in a wider prevention on bullying (S52). Pressure (S46) and bullying issues (S52) were the most consensual statements among the five profiles. Participants were rather indifferent or did not know (scores between -1 and 1 on all factors) for street social workers (Street social workers should be more sensitized to the issue of sexting) (S57) and scholar mediators (School mediators must talk about sexting and do prevention) (S19) as key-actors in sexting issues, an anonymous questions/reports box to be placed at school (S30), prevention posters to create and display in waiting areas (train station, bus stop, shopping center) (S22) and the inclusion of sexting theme in a wider prevention on the Internet (S51).

\section{Discussion}

We identified five profiles that revealed different ways of considering prevention and education surrounding sexting among youths. Even if the first one accounted for the major part of variability, the other four were important in demonstrating diverse opinions. This 
highlighted the need to offer a multidisciplinary, multi-resource, and multi-concept approach to reach all aspects of this practice.

Sexting prevention should not aim at particular persons or in relation to gender. Indeed, the typical scenario that is used in many campaigns illustrating the case of a girl who is victim of a nonconsensual sharing perpetrated by a boy (Barrense-Dias et al., 2018b; Döring, 2014) was not appreciated by participants. They rather called for a universal, nongendered and common message. A one-way gendered perspective could also risk stigmatizing girls, feeding stereotypes and leading to detrimental judgements (Albury \& Crawford, 2012; Krieger, 2017; Ringrose, Gill, Livingstone, \& Harvey, 2012; Salter et al., 2013). While considering the possibility of having boys as victims and girls as perpetrators, youths must be made aware of violent social reactions towards girls (Lippman \& Campbell, 2014; Ringrose et al., 2012; Van Ouytsel et al., 2014; Walker, Sanci, \& Temple-Smith, 2013; Walrave et al., 2015), especially in a sexual context. When a gender difference was assessed more positively (factor 2), the separation of girls and boys in an educational perspective was essentially seen as a way to avoid discomfort and not as a way to differentiate awareness messages, values and knowledge to be transmitted. This separation was also requested by youths in a recent study on sexting education (Jørgensen et al., 2018) and considered as a first step followed by a joint discussion (Van Ouytsel et al., 2014).

Surprisingly, the topic of the Internet was not considered as an appropriate gateway to discuss sexting, demonstrating that sexting is more complex than other online activities. Sexting being practiced primarily with a Smartphone, it is also possible that youths do not necessarily assimilate its use to the use of the Internet. 
Sexting should be included in broader interventions that would highlight and present principles applicable to other activities, such as consent, pressure and respect for others. If an early discussion on sexting from the age of 8 was not considered as appropriate, the above-mentioned principles could however be discussed from a very young age, so that they can be applied later, independently of the practices.

Likewise, youths were also dissatisfied with prevention of consensual sexting, demonstrating that practice-related problems and respect issues need to be discussed directly and independently of the practice per se. These core values are particularly important in light of rapid technological advances. Sexting may be outdated in a few years but other behaviors related to digital tools will certainly appear. Based on the positive ranking of sex education for 4 out of 5 factors, a parallel with sexuality in general should be considered in terms of prevention (Johnson, Mishna, Okumu, \& Daciuk, 2018). It is therefore not by prohibiting and criminalizing consensual sexting that problems linked to this activity can be avoided (Madigan, Ly, Rash, Van Ouytsel, \& Temple, 2018; Powell \& Henry, 2014; Walrave et al., 2015). This result is in line with research (Jørgensen et al., 2018) exploring recommendations from youths themselves to improve education on sexting in school.

Legal issues were considered similarly important on 4 out of 5 factors profiles. However, they were more often considered for nonconsensual sharing to other people or for harassment, pressure, and consent problems, rather than for consensual sexting. Although the police was considered as a good resource in this legal perspective for 2 factors, a multi-resource approach was also highlighted. Indeed, other key-actors, including sex educators and parents, were also considered as potential resources. However, we did not find homogenous results for the key-actors, probably revealing that youths do not know 
exactly whom to address in case of problems and questions about sexting or that they are very different in who they prefer to talk to. As previously recommended (Van Ouytsel et al., 2014), youths must be informed about the resource-persons and a broader multistakeholder strategy should be designed to ensure a large offer and support.

Despite the role that witnesses could play in the case of sexting that goes viral when an intimate content is disseminated without consent (Salmivalli, Poskiparta, Ahtola, \& Haataja, 2013; Van Ouytsel et al., 2014), the ranking of related statements were not very high, except for factor 2 . In a sexting context, and more broadly in a bullying context, there are two kinds of witnesses: the active ones who continue to disseminate an intimate content of someone else and/or take part in the mockeries and the passive ones, who see or know something but say nothing. This result may question the possible lack of consideration or knowledge of the role of passive or active witnesses in the context of sexting problems, and the resolution or the aggravation of the situation (Van Ouytsel et al., 2014; Walker et al., 2013; Walrave et al., 2015). Negative behaviors of witnesses could depend on their empathy for the victim and the victim blame, particularly when personal contents are published (Allison \& Bussey, 2016; Schacter, Greenberg, \& Juvonen, 2016). The statement on victim testimonies that was positively ranked on several factors could illustrate a possible demand and need to improve this empathy and identification. Therefore, prevention approaches must integrate a part on witnesses' behaviors to increase support towards victims and eliminate detrimental judgments leading to double victimization (Schacter et al., 2016; Van Ouytsel et al., 2014; Walrave et al., 2015). For example, the Finish anti-bullying program $\mathrm{KiVa}$ focuses on peers and witnesses and considers that influencing potential victims or perpetrators of bullying will not have an impact if social context is rewarding the behavior (Salmivalli, 2014). 
The first strength of this study is the mixed methodology with quantitative and qualitative data (Jedeloo et al., 2010). Second, to our knowledge, this is the first study that examined the opinions of youths on prevention and education strategies on sexting activities using this methodology. Third, a large set of statements on goals, resources, targets, tools, etc. were offered to the participants to explore the demand of young people regarding sexting prevention. With such a set, we were able to obtain a large overview of the topic and explore different approaches. However, some limitations need to be highlighted. First, the results of this study may not be fully generalizable and mainly brought information on the current viewpoints of the participants (Jedeloo et al., 2010; Wood et al., 2002). However, the combination of shared patterns and quotations contributed to qualitative generalizations (Fairweather \& Rinne, 2012). Second, some youths may have selected more repressive statements thinking that a positive attitude towards sexting would be negatively perceived. In this line of social desirability bias, some participants may not have dared to say that prevention was useless. However, to avoid it, when giving instructions, we made it clear that we were not prevention specialists but researchers without any conflict of interest. Furthermore, when we looked at the individual rankings, the two statements for which there might be doubts about this bias present scores between -4 and 5 for S53 (mean: 1.67) and -5 and 5 for S54 (mean: -3.71 ). Moreover, some authors (Scott et al., 2014) considered that the structure of the Q-Method can counteract such social desirability bias. Third, as we were interested in an overall preventive strategy and in order to avoid influencing their potential responses, we did not collect information on their own sexting activities. But practicing sexting or not could lead to differences in opinions on how to deal with related problems and how to consider it. Fourth, the forced distribution imposed by the grid constrained choices and did not provide the answer I do 
not know. Thus, differences may seem more apparent than in reality. However, such a forced distribution allows direct comparisons between grids because all participants have the same structure and this improves discrimination and stability of data (Watts \& Stenner, 2005). Moreover, we offered them the possibility to write comments. Fifth, even if we collected written explanations on their extreme cards and additional comments, we did not discuss and exchange on the overall grid with the participants.

This study highlighted the need to offer a multidisciplinary, multi-resource and multiconcept approach in prevention surrounding sexting. Broader values and principles such as respect, consent and empathy must be integrated in sexting discussion to consolidate their place in the digital world and ensure a healthy use of media. Consensual sexting must be differentiated, whether in research or intervention, from nonconsensual sharing. Such a separation will enable to communicate clear awareness messages and focus on real problems. All key-actors must deliver the same message. The angle of approach may be different, but the underlying message must go in the same direction to avoid contradictions and misunderstandings. Legal aspects must be reminded in relation to the nonconsensual sharing and the role of witnesses. This strategy could also help to avoid stigmatization of victims in the case of nonconsensual sharing. In this line, youths called expressly for a non-gendered message. Finally, to ensure up-to-date discussions, youths must be involved in the conception of prevention and education strategies to determine the right tools and methods to use. 
Ethical approval: All procedures performed in studies involving human participants were in accordance with the ethical standards of the local research committee (Ethics Committee Vaud) and with the 1964 Helsinki declaration and its later amendments or comparable ethical standards.

Informed consent: Informed consent was obtained from all individual participants included in the study. 


\section{References}

Albury, K., \& Crawford, K. (2012). Sexting, consent and young people's ethics: Beyond Megan's $\quad$ Story. $\quad$ Continum, $\quad 26, \quad 463-473$. doi:https://doi.org/10.1080/10304312.2012.665840

Allison, K. R., \& Bussey, K. (2016). Cyber-bystanding in context: A review of the literature on witnesses' responses to cyberbullying. Child Youth Serv Rev, 65, 183194. doi:https://doi.org/10.1016/j.childyouth.2016.03.026

Barrense-Dias, Y., Akre, C., Berchtold, A., Leeners, B., Morselli, D., \& Suris, J.-C. (2018a). Sexual health and behavior of young people in Switzerland (Raisons de santé 291). Retrieved from Lausanne: http://dx.doi.org/10.16908/issn.1660$\underline{7104 / 291}$

Barrense-Dias, Y., Berchtold, A., Surís, J.-C., \& Akre, C. (2017a). Sexting and the Definition Issue. $J$ Adolesc Health, 61, 544-554. doi:http://dx.doi.org/10.1016/j.jadohealth.2017.05.009

Barrense-Dias, Y., De Puy, J., Romain-Glassey, N., \& Suris, J.-C. (2018b). La prévention et le sexting: un état des lieux. Retrieved from https://www.iumsp.ch/Publications/pdf/rds285_fr.pdf

Barrense-Dias, Y., Suris, J.-C., \& Akre, C. (2017b). La sexualité à l'ère numérique: les adolescents et le sexting (Raisons de santé 269) (1660-7104). Retrieved from Lausanne:

Barrense-Dias, Y., Surís, J.-C., \& Akre, C. (2019). "When It Deviates It Becomes Harassment, Doesn't It?" A Qualitative Study on the Definition of Sexting 
According to Adolescents and Young Adults, Parents, and Teachers. Arch Sex Behav. doi:10.1007/s10508-018-1358-5

Bashatah, L. S. (2016). Q-methodology: What and how? IOSR Journal of Research \& Method in Education, 6(5), 37-43.

Brown, S. R. (1980). Political subjectivity: Applications of $Q$ methodology in political science. New Haven and London: Yale University Press.

Brown, S. R. (1993). A primer on Q methodology. Operant subjectivity, 16(3/4), 91-138.

Brown, S. R. (1996). Q Methodology and Qualitative Research. Qual Health Res, 6(4), 561-567. doi:10.1177/104973239600600408

Crofts, T., \& Lee, M. (2013). 'Sexting,' Children and Child Pornography. Syd Law Rev, 35(1), 85-106.

Döring, N. (2014). Consensual sexting among adolescents: Risk prevention through abstinence education or safer sexting? Cyberpsychology, 8, 1-13. doi:http://dx.doi.org/10.5817/CP2014-1-9

Fairweather, J., \& Rinne, T. (2012). Clarifying a basis for qualitative generalization using approaches that identify shared culture. Qualitative Research, 12(4), 473-485. doi: $10.1177 / 1468794111433000$

Hislop, J., Mason, H., Parr, J. R., Vale, L., \& Colver, A. (2016). Views of Young People With Chronic Conditions on Transition From Pediatric to Adult Health Services. J Adolesc Health, 59(3), 345-353. doi:10.1016/j.jadohealth.2016.04.004

Holoyda, B., Landess, J., Sorrentino, R., \& Friedman, S. H. (2018). Trouble at teens' fingertips: Youth sexting and the law. Behav Sci Law, 36, 170-181. doi:https://doi.org/10.1002/bsl.2335 
Jedeloo, S., van Staa, A., Latour, J. M., \& van Exel, N. J. (2010). Preferences for health care and self-management among Dutch adolescents with chronic conditions: a Q-methodological investigation. Int $J$ Nurs Stud, 47(5), 593-603. doi:10.1016/j.ijnurstu.2009.10.006

Johnson, M., Mishna, F., Okumu, M., \& Daciuk, J. (2018). Non-Consensual Sharing of Sexts: Behaviours and Attitudes of Canadian Youth. Retrieved from Ottawa:

Jørgensen, C. R., Weckesser, A., Turner, J., \& Wade, A. (2018). Young people's views on sexting education and support needs: findings and recommendations from a UK-based study. $\quad$ Sex $\quad$ Educ, $1-16$. doi:http://dx.doi.org/10.1080/14681811.2018.1475283

Klettke, B., Hallford, D. J., \& Mellor, D. J. (2014). Sexting prevalence and correlates: A systematic literature review. Clin Psychol Rev, 34, 44-53. doi:https://doi.org/10.1016/j.cpr.2013.10.007

Krieger, M. A. (2017). Unpacking "Sexting": A Systematic Review of Nonconsensual Sexting in Legal, Educational, and Psychological Literatures. Trauma Violence Abuse, 18(5), 593-601. doi:10.1177/1524838016659486

Levick, M., \& Moon, K. (2010). Prosecuting sexting as child pornography. Valparaiso Univ Law Rev, 44(4), 1035-1054.

Lippman, J. R., \& Campbell, S. W. (2014). Damned If You Do, Damned If You Don't...If You're a Girl: Relational and Normative Contexts of Adolescent Sexting in the United States. $\quad J \quad$ Child $\quad$ Media, $\quad 8, \quad 371-386$. doi:https://doi.org/10.1080/17482798.2014.923009

Madigan, S., Ly, A., Rash, C. L., Van Ouytsel, J., \& Temple, J. R. (2018). Prevalence of Multiple Forms of Sexting Behavior Among Youth: A Systematic Review and 
$\begin{array}{llll}\text { Meta-analysis. } & \text { JAMA } & \text { Pediatr, } & \text { 172(4), }\end{array}$ doi:10.1001/jamapediatrics.2017.5314

Powell, A., \& Henry, N. (2014). Blurred Lines? Responding to 'Sexting' and Genderbased Violence among Young People. Children Australia, 39(2), 119-124. doi:10.1017/cha.2014.9

Pro Juventute. (2013). Campagne de sensibilisation "Sexting". Retrieved from https://www.projuventute.ch/Sexting-2013-2014.2477.0.html?\&L=1

Ramlo, S. E., \& Newman, I. (2011). Q methodology and its position in the mixed methods continuum. Operant subjectivity, 34(3), 172-191.

Ringrose, J., Gill, R., Livingstone, S., \& Harvey, L. (2012). A qualitative study of children, young people and 'sexting': A report prepared for the NSPCC. Retrieved from London: $\quad$ https://www.nspcc.org.uk/services-andresources/research-and-resources/pre-2013/qualitative-study-sexting/

Salmivalli, C. (2014). Participant Roles in Bullying: How Can Peer Bystanders Be Utilized in Interventions? Theory Into Practice, 53(4), 286-292. doi:10.1080/00405841.2014.947222

Salmivalli, C., Poskiparta, E., Ahtola, A., \& Haataja, A. (2013). The Implementation and Effectiveness of the KiVa Antibullying Program in Finland. European Psychologist, 18(2), 79-88. doi:10.1027/1016-9040/a000140

Salter, M., Crofts, T., \& Lee, M. (2013). Beyond criminalisation and responsibilisation: Sexting, gender and young people. Current Issues in Criminal Justice, 24(3), 301316. 
Schacter, H. L., Greenberg, S., \& Juvonen, J. (2016). Who's to blame?: The effects of victim disclosure on bystander reactions to cyberbullying. Comput Human Behav, 57, 115-121. doi:https://doi.org/10.1016/j.chb.2015.11.018

Scott, S., Baker, R., Shucksmith, J., \& Kaner, E. (2014). Autonomy, special offers and routines: a Q methodological study of industry-driven marketing influences on young people's drinking behaviour. Addiction, 109(11), 1833-1844. doi:10.1111/add.12663

Shinebourne, P. (2009). Using Q Method in Qualitative Research. Int J Qual Methods, 8(1), 93-97. doi:10.1177/160940690900800109

Shinebourne, P., \& Adams, M. (2007). Q-methodology as a phenomenological research method. Existential Analysis(18), 103-116.

Stephenson, W. (1935). Correlating Persons Instead of Tests. J Pers, 4(1), 17-24. doi:10.1111/j.1467-6494.1935.tb02022.x

Suter, L., Waller, G., Bernath, J., Külling, C., Willemse, I., \& Süss, D. (2018). JAMES Jeunes, activités, médias - enquête Suisse: Rapport sur les résultats de l'étude JAMES 2018. Retrieved from Zurich: https://www.swisscom.ch/content/dam/swisscom/fr/about/entreprise/durabilite/c ompetencesmedias/documents/rapport-james-2018.pdf

The National Campaign to Prevent Teen and Unplanned Pregnancy. (2008). Sex and Tech: Results From a Survey of Teens and Young Adults. Retrieved from Washington, DC:

Tielen, M., van Staa, A. L., Jedeloo, S., van Exel, N. J., \& Weimar, W. (2008). Qmethodology to identify young adult renal transplant recipients at risk for 
nonadherence.

Transplantation,

$85(5)$,

700-706.

doi:10.1097/TP.0b013e318166163e

Van Ouytsel, J., Walrave, M., \& Ponnet, K. (2018). Adolescent sexting research: The challenges ahead. JAMA Pediatr, 172, 405-406. doi:https://doi.org/10.1001/jamapediatrics.2018.0013

Van Ouytsel, J., Walrave, M., \& Van Gool, E. (2014). Sexting: Between Thrill and FearHow Schools Can Respond. The Clearing House: A Journal of Educational Strategies, Issues and Ideas, 87(5), 204-212. doi:10.1080/00098655.2014.918532

Walker, S., Sanci, L., \& Temple-Smith, M. (2013). Sexting: young women's and men's views on its nature and origins. $J$ Adolesc Health, 52, 697-701. doi:https://dx.doi.org/10.1016/j.jadohealth.2013.01.026

Walrave, M., Ponnet, K., Van Ouytsel, J., Van Gool, E., Heirman, W., \& Verbeek, A. (2015). Whether or not to engage in sexting: Explaining adolescent sexting behaviour by applying the prototype willingness model. Telematics and Informatics, 32, 796-808. doi:https://doi.org/10.1016/j.tele.2015.03.008

Watts, S., \& Stenner, P. (2005). Doing Q methodology: theory, method and interpretation. Qual Res Psychol, 2(1), 67-91. doi:10.1191/1478088705qp022oa

Wolak, J., \& Finkelhor, D. (Producer). (2011). Sexting: A typology. Retrieved from http://unh.edu/ccrc/pdf/CV231_Sexting\%20Typology\%20Bulletin_4-6-

\section{$\underline{11 \_ \text {revised.pdf }}$}

Wolfe, S. E., Marcum, C. D., Higgins, G. E., \& Ricketts, M. L. (2016). Routine Cell Phone Activity and Exposure to Sext Messages:Extending the Generality of Routine Activity Theory and Exploring the Etiology of a Risky Teenage Behavior. Crime Delinquency, 62(5), 614-644. doi:10.1177/0011128714541192 
Wood, R. T. A., Griffiths, M. D., Derevensky, J. L., \& Gupta, R. (2002). Adolescent Accounts of the UK National Lottery and Scratchcards: An Analysis Using QSorts. J Gambl Stud, 18(2), 161-183. doi:10.1023/A:1015576731887 
Table 1 Characteristics of participants and factor on which they are best represented

\begin{tabular}{|c|c|c|c|}
\hline Participant & Sex & Age & Assigned factor ${ }^{\mathrm{a}}$ \\
\hline 1 & Female & 16 & Factor 2 \\
\hline 2 & Female & 17 & Factor 5 \\
\hline 3 & Female & 16 & Factor 5 \\
\hline 4 & Female & 16 & Factor 5 \\
\hline 5 & Female & 18 & Factor 1 \\
\hline 6 & Female & 15 & Factor 4 \\
\hline 7 & Female & 17 & Factor 4 \\
\hline 8 & Male & 17 & Factor 1 \\
\hline 9 & Female & 15 & Factor 5 \\
\hline 10 & Female & 15 & Factor 2 \\
\hline 11 & Male & 17 & Factor 5 \\
\hline 12 & Female & 18 & Factor 3 \\
\hline 13 & Male & 17 & Factor 5 \\
\hline 14 & Female & 15 & Factor 1 \\
\hline 15 & Female & 15 & Factor 1 \\
\hline 16 & Female & 16 & Factor 3 \\
\hline 17 & Female & 15 & Factor 1 \\
\hline 18 & Female & 13 & Factor 1 \\
\hline 19 & Female & 17 & Factor 3 \\
\hline 20 & Male & 14 & Factor 2 \\
\hline 21 & Female & 16 & Factor 1 \\
\hline
\end{tabular}




\begin{tabular}{|c|c|c|c|}
\hline 22 & Female & 15 & Factor 4 \\
\hline 23 & Male & 18 & Factor 4 \\
\hline 24 & Female & 17 & Factor 1 \\
\hline 25 & Female & 17 & Factor 2 \\
\hline 26 & Male & 17 & Factor 4 \\
\hline 27 & Male & 18 & Factor 5 \\
\hline 28 & Female & 18 & Factor 3 \\
\hline 29 & Female & 17 & Factor 3 \\
\hline 30 & Female & 18 & Factor 4 \\
\hline 31 & Female & 18 & Factor 4 \\
\hline 32 & Male & 18 & Factor 1 \\
\hline 33 & Female & 18 & Factor 2 \\
\hline 34 & Female & 17 & Factor 5 \\
\hline 35 & Female & 14 & Factor 5 \\
\hline 36 & Male & 17 & Factor 3 \\
\hline 37 & Male & 15 & Factor 1 \\
\hline 38 & Male & 16 & Factor 1 \\
\hline 39 & Male & 15 & Factor 2 \\
\hline 40 & Male & 16 & Factor 4 \\
\hline 41 & Male & 15 & Factor 1 \\
\hline 42 & Male & 17 & Factor 1 \\
\hline 43 & Male & 16 & Factor 5 \\
\hline 44 & Male & 15 & Factor 2 \\
\hline
\end{tabular}




\begin{tabular}{|c|c|c|c|}
\hline 45 & Male & 16 & Factor 2 \\
\hline 46 & Male & 17 & Factor 1 \\
\hline 47 & Male & 15 & Factor 2 \\
\hline 48 & Male & 14 & Factor 4 \\
\hline
\end{tabular}

${ }^{a}$ Bold type represent the most representative Q-sorts for each factor (flagged) or the Qsorts that defined each factor, italic type represent less representative Q-sorts or Q-sorts that did not define a factor (not flagged but the higher loading for the factor) 
Table 2 Mean age and gender repartition of participants for each factor, overall and flagged

\begin{tabular}{|l|c|c|c|c|}
\hline & $\begin{array}{c}\text { Mean age } \\
\text { (overall) }\end{array}$ & $\begin{array}{c}\text { Mean age } \\
\text { (flagged) }\end{array}$ & $\begin{array}{c}\text { \% of females } \\
\text { (overall) }\end{array}$ & $\begin{array}{c}\text { of females } \\
\text { (flagged) }\end{array}$ \\
\hline Factor 1 & 15.9 & 15.8 & 50.0 & 66.7 \\
\hline Factor 2 & 15.7 & 16.2 & 44.0 & 75.0 \\
\hline Factor 3 & 17.2 & 17.3 & 83.3 & 66.7 \\
\hline Factor 4 & 16.4 & 17.0 & 55.5 & 66.7 \\
\hline Factor 5 & 16.3 & 16.5 & 60.0 & 50.0 \\
\hline
\end{tabular}


Table 3 List of statements (Q-set) and factor scores

The scores of the 10 statements ranking the more extremely $(-4,-5,+4,+5)$ on each factor appear on a grey background, the darkest indicating the most extreme scores

Consensus statements are in italic (19, 22, 23, 30, 34, 46, 50, 51, and 52), Z-score is statistically similar for the five factors

\begin{tabular}{|c|c|c|c|c|c|c|}
\hline \multirow[b]{2}{*}{ No } & \multirow{2}{*}{ Statement } & \multicolumn{5}{|c|}{ Factor } \\
\hline & & A & $\mathrm{B}$ & $\mathrm{C}$ & $\mathrm{D}$ & $\mathrm{E}$ \\
\hline 1 & Sex education classes should address sexting & 3 & 4 & $-1^{\mathrm{a}}$ & 3 & 3 \\
\hline 2 & $\begin{array}{l}\text { A parental filter / control should be added to mobile phones to monitor } \\
\text { messages }\end{array}$ & $-5^{\mathrm{a}}$ & -2 & $0^{\mathrm{b}}$ & -3 & -2 \\
\hline 3 & $\begin{array}{l}\text { Prevention should focus on the sharing of content (text, audio, photo, } \\
\text { video) between two consenting persons (consensual sexting) }\end{array}$ & 1 & 0 & -2 & -1 & -2 \\
\hline 4 & $\begin{array}{l}\text { Prevention should focus on the nonconsensual dissemination of } \\
\text { content (text, audio, photo, video) to other people }\end{array}$ & 3 & 3 & 4 & $-3^{\mathrm{a}}$ & 3 \\
\hline 5 & Prevention should be different between boys and girls & -4 & $2^{b}$ & -4 & -2 & -4 \\
\hline 6 & Prevention should be different according to age & -2 & -1 & 0 & 2 & 3 \\
\hline 7 & Prevention linked to sexting should start at the age of 8 & -3 & -2 & -3 & $-1^{b}$ & -4 \\
\hline 8 & $\begin{array}{l}\text { Youths should be involved in developing prevention messages / } \\
\text { campaigns }\end{array}$ & $-1^{\mathrm{a}}$ & 3 & 3 & 1 & 1 \\
\hline 9 & Schools must offer discussion / debate areas to talk about sexting & 1 & -2 & 0 & 1 & -2 \\
\hline 10 & More training / information on sexting is needed for parents & -2 & 0 & -2 & 2 & 1 \\
\hline 11 & More training / information on sexting is needed for youths & 0 & 2 & -1 & 5 & 5 \\
\hline 12 & More training / information on sexting is needed for teachers & -1 & 1 & 0 & 2 & 2 \\
\hline
\end{tabular}




\begin{tabular}{|c|c|c|c|c|c|c|}
\hline 13 & $\begin{array}{l}\text { A prevention spot on sexting must be created and shown during } \\
\text { cinema commercials }\end{array}$ & -3 & -1 & -2 & 0 & 1 \\
\hline 14 & $\begin{array}{l}\text { A prevention spot on sexting must be created and shown during } \\
\text { television commercials }\end{array}$ & -2 & 1 & 1 & 1 & -1 \\
\hline 15 & $\begin{array}{l}\text { A prevention spot on sexting must be created with Youtubers or } \\
\text { Vloggers }\end{array}$ & $-3^{\mathrm{a}}$ & 2 & 3 & 1 & 2 \\
\hline 16 & $\begin{array}{l}\text { A Smartphone app on sexting must be created (for example to ask for } \\
\text { help) }\end{array}$ & 0 & 2 & -2 & -1 & 0 \\
\hline 17 & Police must do prevention on sexting in class & 2 & -2 & -2 & -1 & $5^{b}$ \\
\hline 18 & Teachers must talk about sexting and do prevention & $-2^{\mathrm{a}}$ & 0 & 1 & 2 & 0 \\
\hline 19 & School mediators must talk about sexting and do prevention & 0 & 1 & 0 & 0 & 0 \\
\hline 20 & $\begin{array}{l}\text { Prevention should target the witnesses who continue to disseminate a } \\
\text { content (active witness) }\end{array}$ & -1 & 3 & 2 & -1 & -1 \\
\hline 21 & Parents must talk about sexting and do prevention & -3 & -3 & -1 & $4^{\mathrm{b}}$ & 2 \\
\hline 22 & $\begin{array}{l}\text { Prevention posters must be created and displayed in waiting areas } \\
\text { (train station, bus stop, shopping center) }\end{array}$ & 0 & -1 & 0 & 0 & 0 \\
\hline 23 & Prevention posters must be created and displayed in the streets & 0 & -2 & -2 & 0 & 0 \\
\hline 24 & $\begin{array}{l}\text { Establishing a system of big brother / sister who would come to talk } \\
\text { about sexting (a young person who comes to speak to the youths) }\end{array}$ & -1 & 0 & -1 & -1 & $4^{b}$ \\
\hline 25 & $\begin{array}{l}\text { Youths must be informed of the legal consequences linked to sexting } \\
\text { (articles of law, penalties, prison) }\end{array}$ & 5 & 5 & $0^{\mathrm{a}}$ & 3 & 4 \\
\hline 26 & Testimonies of victims in a case related to sexting must be used & 4 & 5 & 4 & 3 & $-2^{a}$ \\
\hline 27 & A special phone line for sexting problems must be created & $4^{\mathrm{b}}$ & 2 & -1 & 0 & 0 \\
\hline 28 & Sexting must be forbidden even between two consenting persons & -3 & -4 & -3 & $-2^{b}$ & -3 \\
\hline
\end{tabular}




\begin{tabular}{|c|c|c|c|c|c|c|}
\hline 29 & Boys and girls must be separated when a discussion on sexting is done & -4 & $3^{\mathrm{b}}$ & -3 & -3 & -4 \\
\hline 30 & An anonymous questions / reports box must be placed at school & 0 & 1 & 0 & -1 & -1 \\
\hline 31 & $\begin{array}{l}\text { Posters / flyers of information on reference persons to contact in case } \\
\text { of problems linked to sexting should be created }\end{array}$ & 3 & 0 & 3 & 1 & 0 \\
\hline 32 & A website dedicated to sexting should be created & 2 & 0 & 1 & 1 & -1 \\
\hline 33 & Prevention linked to sexting is useless & -4 & -5 & -4 & -5 & -3 \\
\hline 34 & $\begin{array}{l}\text { Prevention should target the people who disseminate the content } \\
\text { without consent }\end{array}$ & 1 & 1 & 2 & 0 & 2 \\
\hline 35 & $\begin{array}{l}\text { Prevention should target the witnesses of problems who say nothing } \\
\text { (passive witnesses) }\end{array}$ & -1 & 1 & 2 & -2 & 1 \\
\hline 36 & Prevention should target potential victims to protect themselves & -1 & 0 & $3^{b}$ & $-3^{\mathrm{a}}$ & 1 \\
\hline 37 & Prevention related to sexting should address consent issues & 1 & 4 & 1 & 4 & 2 \\
\hline 38 & $\begin{array}{l}\text { A procedure to follow (step by step) in case of problems related to } \\
\text { sexting should be created }\end{array}$ & 2 & 0 & $5^{b}$ & -2 & -2 \\
\hline 39 & $\begin{array}{l}\text { An online chat system to get help in case of sexting problems should } \\
\text { be created }\end{array}$ & 2 & 1 & 0 & 0 & -1 \\
\hline 40 & Prevention should address respect for others & 3 & 1 & 1 & 4 & 3 \\
\hline 41 & $\begin{array}{l}\text { Interactive activities such as role plays involving a victim, an author } \\
\text { and a witness should be created }\end{array}$ & 2 & $-3^{a}$ & 1 & 0 & -1 \\
\hline 42 & Humor should be used to do prevention on sexting & 0 & -3 & -1 & -1 & -3 \\
\hline 43 & $\begin{array}{l}\text { Prevention related to sexting should address risk of depression and } \\
\text { malaise }\end{array}$ & 5 & 0 & 2 & 5 & 2 \\
\hline 44 & Prevention related to sexting should address bullying and blackmail & 4 & 0 & 5 & 3 & 1 \\
\hline
\end{tabular}




\begin{tabular}{|c|c|c|c|c|c|c|}
\hline 45 & $\begin{array}{l}\text { Funny pictures to send in case of demand should be created (example: } \\
\text { a banana to represent the male sex) }\end{array}$ & 0 & -3 & -3 & 1 & 0 \\
\hline 46 & $\begin{array}{l}\text { Prevention related to sexting should address pressure that can } \\
\text { sometimes be experienced to obtain a photo / video }\end{array}$ & 3 & 4 & 2 & 2 & 4 \\
\hline 47 & $\begin{array}{l}\text { Prevention should highlight girls as victims and boys as authors of } \\
\text { dissemination }\end{array}$ & -5 & $-1^{b}$ & -4 & -3 & -5 \\
\hline 48 & $\begin{array}{l}\text { Online interactive videos or games in which a person play a role and } \\
\text { choose actions should be created }\end{array}$ & -1 & -2 & $1^{\mathrm{b}}$ & -2 & -1 \\
\hline 49 & $\begin{array}{l}\text { Prevention related to sexting should address victim support if a photo / } \\
\text { video is disseminated without consent }\end{array}$ & 2 & -1 & 2 & 3 & 1 \\
\hline 50 & Sexting workshops during special days / weeks should be offered & -1 & -1 & 0 & -2 & -1 \\
\hline 51 & Sexting theme should be included in a wider prevention on the Internet & 1 & -1 & 1 & 1 & 0 \\
\hline 52 & Sexting theme should be included in a wider prevention on bullying & 1 & 2 & 3 & 2 & 3 \\
\hline 53 & Prevention is useful for problems linked to sexting & 1 & 3 & 4 & 0 & 1 \\
\hline 54 & Doing nothing / not practicing sexting is the best prevention & $-2^{b}$ & -5 & -5 & -5 & -5 \\
\hline 55 & $\begin{array}{l}\text { Prevention is done alone or automatically when a problem occurs in a } \\
\text { school (example: a photo disseminated throughout the school) }\end{array}$ & 0 & -3 & -1 & -4 & -2 \\
\hline 56 & It is impossible to prevent problems linked to sexting & $0^{\mathrm{b}}$ & -4 & -5 & -4 & -3 \\
\hline 57 & Street social workers should be more sensitized to the issue of sexting & 1 & -1 & -1 & 0 & 0 \\
\hline 58 & $\begin{array}{l}\text { Prevention related to sexting should be done in specific group such as } \\
\text { scouts, sports association, etc. }\end{array}$ & $-2^{\mathrm{b}}$ & -4 & -3 & -4 & -3 \\
\hline
\end{tabular}

${ }^{a} z$-Score for the statement is lower (disagree more) than in all of the other factors

${ }^{b} z$-Score for the statement is higher (agree more) than in all of other factors 
Figure 1 Score sheet to rank-order the 58 statements

\begin{tabular}{|c|c|c|c|c|c|c|c|c|c|c|}
\hline-5 & -4 & -3 & -2 & -1 & 0 & +1 & +2 & +3 & +4 & +5 \\
\hline & & & & & & & & & & \\
\hline & & & & & & & & & & \\
\hline & & & & & & & & & & \\
\hline & & & & & & & & & & \\
\hline & & & & & & & & & & \\
\hline & & & & & & & & & & \\
\hline & & & & & & & & & & \\
\hline & & & & & & & & & & \\
\hline
\end{tabular}

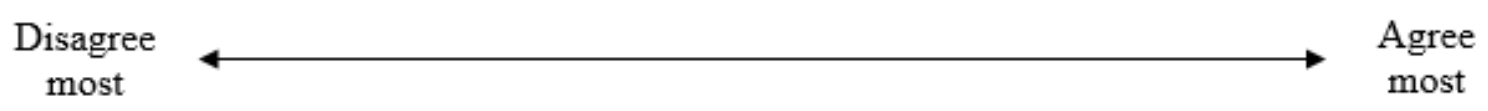

Figure 2 Explanatory Sequential Design

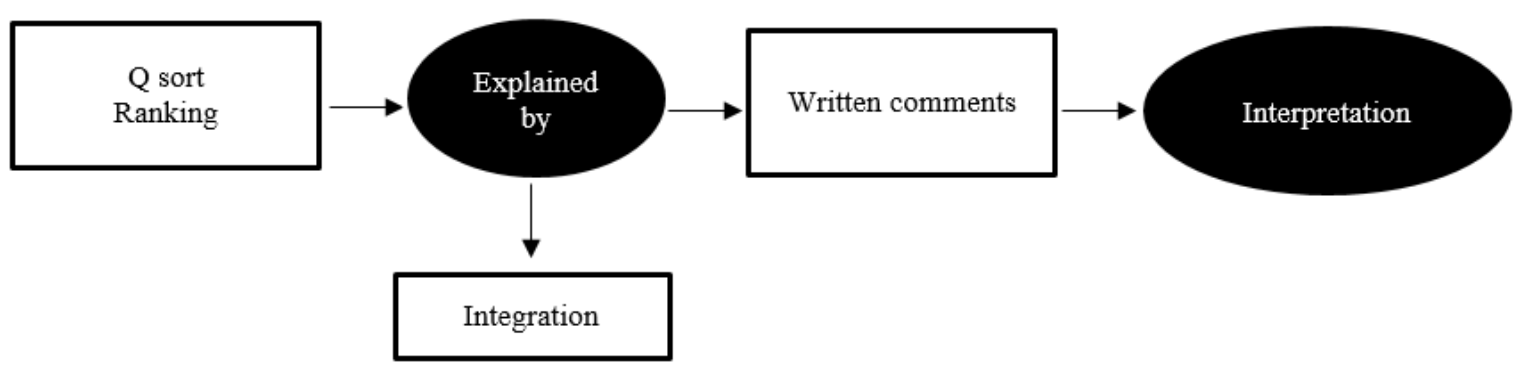

